\title{
Safety measures to prevent workplace violence in emergency primary care centres-a cross-sectional study
}

Tone Morken ${ }^{1,2^{*}}$ and Ingrid H Johansen ${ }^{1}$

\begin{abstract}
Background: Employees in emergency primary care centres (EPCC) have raised personal safety as an issue. Despite a high risk of experiencing workplace violence at EPCCs in Norway, knowledge regarding applied preventive measures is limited. The description of existing safety measures is an important prerequisite to evaluate and make guidelines for the improvement of preventive practices on a national level. The objective of this study was to investigate to which extent general practitioners work alone in EPCCs in Norway, and to estimate the prevalence of other preventive measures against workplace violence.
\end{abstract}

Methods: A survey was sent to the managers of all 210 registered EPCCs in Norway. The questionnaire included 22 items on safety measures, including available staff, architecture and outfitting of the reception and consulting rooms, and the availability of electronic safety systems and training or monitoring systems. The data were analysed using descriptive statistics. Differences between EPCCs staffed by one general practitioner alone and EPCCs with more health personnel on duty were explored.

Results: Sixty-one (30\%) of the 203 participating EPCCs had more than one person on duty round-the-clock. These EPCCS reported the application of a significantly higher number of safety measures compared to the EPCCS with only one general practitioner on duty during some or part of the 24 hours. Examples of safety measures being more common in highly staffed EPCCs were automatic door locks ( $<<0.001)$, arrangement of furniture in the consulting room ensuring that the patient is not seated between the clinician and the exit $(p=0.014)$, the possibility of bringing an extra person on emergency call-outs or home visits when needed for security reasons $(p=0.014)$, and having organised training regarding violence $(p<0.001)$.

Conclusion: This study shows considerable differences between Norwegian EPCCs regarding applied preventive measures, and a higher prevalence of such measures in EPCCs staffed with several health personnel around-the -clock. More research is needed to understand the reasons for, and the effects of, these differences.

\section{Background}

Employees in emergency primary care centres (EPCC) in Norway have raised concerns about personal safety and the lack of adequate security precautions to prevent violence in the workplace. Workplace violence can be defined as "incidents in which an employee is abused, sexually harassed, or assaulted in circumstances related to their work, involving an explicit or implicit challenge

\footnotetext{
* Correspondence: tone.morken@uni.no

'National Centre for Emergency Primary Health Care, Uni Health, Uni Research, Bergen, Norway

${ }^{2}$ Department of Global Public Health and Primary Care, University of Bergen, Bergen, Norway
}

\section{Biomed Central}

(c) 2013 Morken and Johansen; licensee BioMed Central Ltd. This is an open access article distributed under the terms of the Creative Commons Attribution License (http://creativecommons.org/licenses/by/2.0), which permits unrestricted use,

distribution, and reproduction in any medium, provided the original work is properly cited. to their safety, well-being or health" [1]. A recent study has shown a high prevalence of workplace violence in Norwegian EPCCs: One in three employees has been physically abused during their career [2].

In Norway, the local municipalities are legally responsible for the 24/7 emergency medical services for all inhabitants [3]. During office hours, the emergency medical service is usually provided at general practitioners' (GP) clinics, whilst EPCCs provide medical care during evenings, nights, weekends and public holidays. Some of the EPCCs are organised collaboratively between two or more municipalities. The number of staff present at any given time, including GPs (mandatory), 
nurses and other health personnel, varies between the EPCCs from one to more than ten persons on duty, from the smallest in the rural districts to the largest in the urban districts [4]. The GPs primarily treat patients at the centre, but they also carry out home visits and participate in on-site emergencies away from hospitals [5]. When nurses or other health personnel are present, they perform triage on patients who contact the centre, give advice when appropriate and assist the GP when needed.

Due to Norway's strict two-tiered health care system, patients are not allowed to present themselves directly to hospital emergency departments. Out-of-hours they have to contact EPCCs when in need of medical aid. A referral from the EPCC's GP is a prerequisite for access to secondary care. Patients self-refer to the EPCCs. As a matter of policy, EPCCs are therefore easily accessible to the public, and they handle all types of emergencies, including psychiatric emergency situations. The contact rates vary between the EPCCs from about 300 to 650 per 1000 inhabitants per year [6].

Emergency medicine and psychiatry have been singled out as high risk areas for experiencing workplace violence [7]. Despite the risk of workplace violence at EPCCs, there has been little focus on prevention. However, apprehension about violence has been found to be high in general practice [8] and in out-of-hours services in particular [9]. In a study of GPs' experiences in Norwegian EPCCs, the GPs spontaneously raised personal safety as an issue [10]. They talked about problems with being alone and being completely left to their own device. They also reported low safety awareness at the centres.

Little is known regarding applied preventive measures. The description of existing safety measures is an important prerequisite to evaluate and make guidelines for the improvement of preventive practices on a national level. Thus, the objective of this study was to investigate to which extent GPs work alone in EPCCs in Norway, and to estimate the prevalence of applied measures to prevent workplace violence.

\section{Methods}

In 2012, a web-based questionnaire was sent to the managers of each of the 210 registered EPCC in Norway. The questionnaire was part of an update of the National register for organisational data of all EPCCs in Norway, a register kept by request from The Norwegian Ministry of Health and Care Services. The register includes names of the manager for each of the EPCCs. Individual respondents (the managers) were thus identifiable. Every individual question on the online questionnaire had to be answered to proceed in the survey; hence there were no missing data in the completed questionnaires. The questionnaire was mainly about organisational information (management, staffing, equipment), and included a question regarding the application of 22 safety measures based on recommendations from the Norwegian Association of General Practitioners [11].

For analytic purposes, the 22-item list was grouped into five categories: (1) available staff, (2) reception, (3) consulting room, (4) electronic safety systems and (5) training/ monitoring systems. The data were analysed using SPSS version 19. Differences in prevalence of safety measures between EPCCs with only one GP on duty and more highly staffed EPCCs were tested with Pearson chi-squared test. Statistically significance was accepted at $\mathrm{p}<0.05$.

The study was based on data from a survey used to update a national register, which is approved by the Norwegian Social Science Data Services. The survey involved organisational data only, and was not affected by the Norwegian Health Research Act. An approval from an ethics committee was therefore not needed [12].

\section{Results}

A total of 203 (97\%) of the 210 eligible EPCCs completed the questionnaire. Table 1 shows the prevalence of occupational safety measures applied.

\section{Available staff}

Only 30.0\% of the EPCCs always had more than one person on duty. In less than half of the EPCCs (44.3\%) an extra person could come on call-outs or home visits when needed for security reasons. Four EPPCs (2.0\%) had applied every single measure in the availablestaff-category, i.e. always more than one person on duty, personnel continuously accessible for patients/ visitors, routines for an extra person on call-outs and home visits when needed for security reasons, and security guards always present. Sixty-eight centres (33.5\%) had applied none of the four measures.

\section{Prevalence of other measures}

The most frequently applied safety measure in the reception was a barrier or glass partition between the reception and the waiting room, reported by 176 centres (86.7\%). This was also the most frequently applied of all 22 safety measures in question. A total of 54 centres (26.6\%) reported that they had applied all measures related to the physical environment in reception areas, i.e. a barrier in place between reception and waiting room, a clear view to the entrance and the waiting room, and availability of sheltered rooms. Fourteen centres (6.9\%) had none of these measures.

The most frequently applied measure related to the consulting room was the provision of an alternative exit, reported by 120 centres (59.1\%). Thirty-eight centres (18.7\%) had applied all measures, i.e. arrangement of furniture so that the patient did not sit between the 
Table 1 Prevalence of occupational safety measures in Norwegian emergency primary care centres $(n=203)$

Available staff

Extra person on call-out/home visits when needed for security reasons

Personnel continuously accessible for patients/visitors

Always more than one person on duty

Security guard

$90 \quad(44.3)$

$90 \quad(44.3)$

$61 \quad(30.0)$

$7 \quad(3.4)$

\section{Reception}

Barrier/glass partition between reception and waiting room

View to the waiting room

$176 \quad(86.7)$

View to the entrance

Sheltered room

Consulting room

Alternative exit

Quick entrance/exit for staff

Patient NOT sitting between clinician and door

Electronic safety systems

Alarm on medical radio network

Automatic door lock

Panic button by desk/keyboard

Alarm linked to alarm center

Poster with information about alarm

Portable alarm

CCTV (closed-circuit television) camera

Panic button on wall

$84 \quad(41.4)$

Education and reporting system

Follow-up of employees after experienced violence

$150(74.9)$

Monitoring system of violence against personnel

$150(74.9)$

Training regarding violence against personnel

clinician and the door, easily accessible entrance/exit for staff, and an alternative exit from the consulting room. Fifty-five centres (27.1\%) had none of these recommended measures.

In the electronic equipment category the medical radio was the safety system most often used, applied by 151 centres $(74.4 \%)$. One centre $(0.5 \%)$ reported that all measures in this category were employed, including closecircuit television (CCTV) cameras, automatic door locks, alarms on the medical radio, panic buttons by the desk or keyboard, wall-mounted panic buttons, portable alarms, alarms linked to an alarm centre, and information posters about alarms. Nine centres (4.4\%) employed none of these measures.

Most EPCCs stated that they had a system to followup employees who had experienced incidents of violence ( $n=150,74.9 \%)$. Seventy-five EPCCs (36.9\%) had applied all measures regarding training and monitoring, including training regarding violence against personnel, incident reporting of episodes and follow-up of employees who had experienced incidents of violence. Thirty-five EPCCs (17.2\%) reported that none of these measures were implemented.

\section{Differences between EPCCs with one on duty and EPCCS with more than one on duty}

Most safety measures were significantly more prevalent at EPCCs which had more than one person present around the clock compared with the other EPCCs (Table 2). The only safety measure more frequently applied at EPCCs with only one GP on duty without support from other health personnel, was the use of the alarm on the medical network $(\mathrm{p}<0.001)$.

\section{Discussion}

To our knowledge, this is the first study on preventive measures in EPCCs in Norway. The study shows a high variation in the number of occupational safety measures applied. The reported variation in applied measures could reflect differences in perceived needs, due to differences in number or severity of violent incidents. However, it may also reflect a variation in organisational models, as larger organisations might allow more focus on administrative factors. This is further supported by the finding that implementation of most safety measures was significantly lower at EPCCs with only one GP present compared to EPCCs with more staff.

The study had a high response rate. The results are therefore likely to be representative of the managers of Norwegian EPCCs. However, because respondents did not retain anonymity, the validity of the study might have been compromised by managers trying to push a political statement in their response. As the 22-item list of measures was based on general recommendations from the Norwegian Association of General Practitioners, the list might include measures of limited relevance to the EPCCs. Furthermore, the list may lack essential preventive measures [13]. The effect of preventive measures on number of violent incidents is not known, and intervention studies are therefore needed. Nevertheless, our study gives an overview of the reported application of preventive measures, and the results provide insight into general preparedness regarding workplace violence.

Available staff is regarded as especially relevant as a safety measure to prevent workplace violence in EPCC. The presence of co-workers has been identified as a potential deterrent to assaults [14] and has also been recommended in an action plan proposal regarding organisation of emergency services in Norwegian primary health care [15]. It is therefore particularly worrying that the majority of GPs work alone for at least some of the 
Table 2 Occupational safety measures in EPCCs* with $>1$ person present $(n=61)$ compared to others $(n=142)$

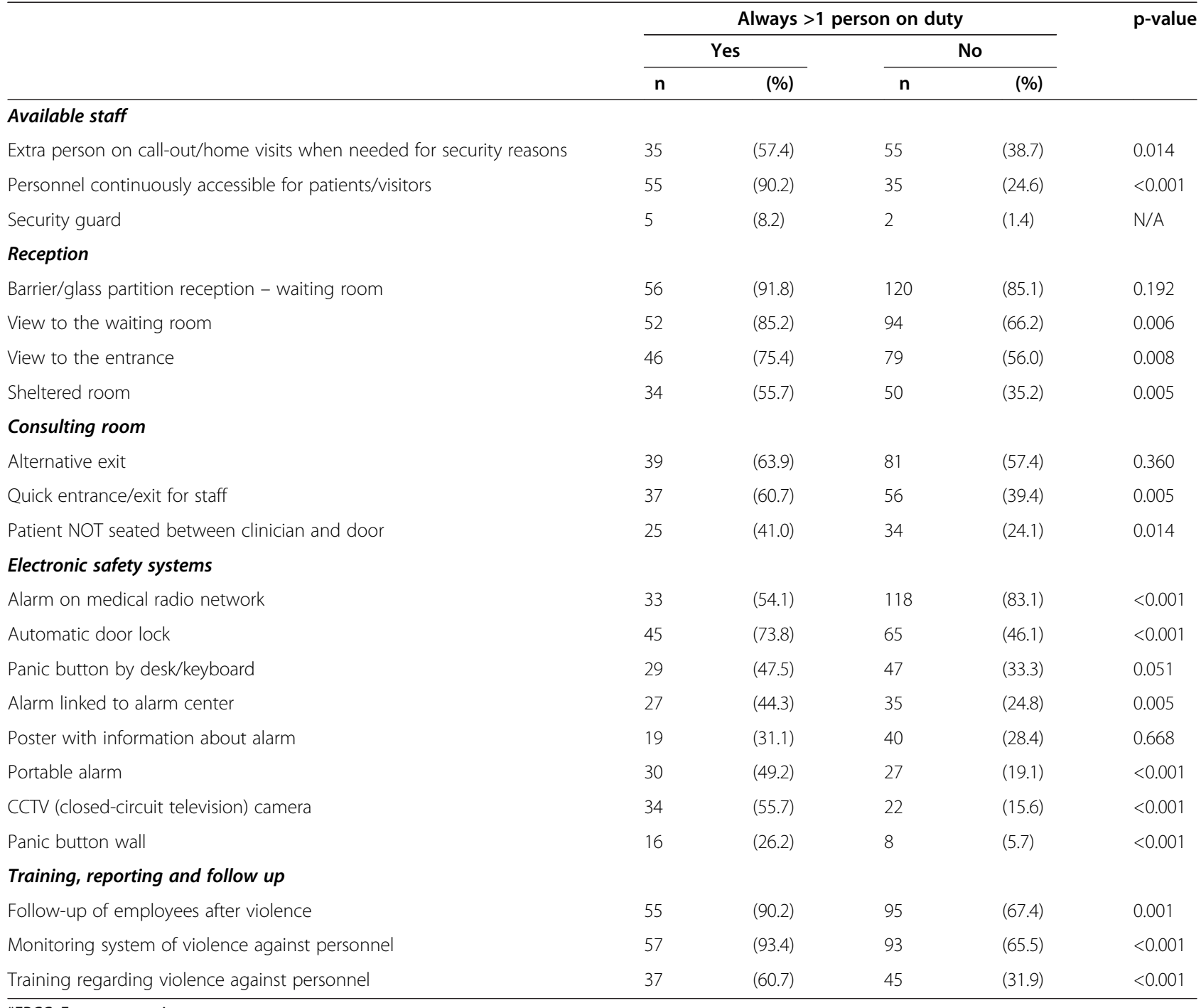

*EPCC: Emergency primary care centre.

time during opening hours, as this renders them more vulnerable should violent situations occur.

Some of the recommended measures related to the reception area and the consulting room are difficult to implement without changing the building structure. They must therefore be included in the initial planning phase of a new EPCC. Approximately one third of the EPCCs had none of the recommended measures regarding the consulting room. This suggests that prevention of workplace violence is often ignored in the process of planning or redesigning the EPCCs. The safety measure "patient NOT sitting between clinician and door" had the lowest prevalence in the consulting room category, though it might be rather easy to implement and possibly of high significance. Having a barrier or glass partition around the reception desk was common and can often be implemented without major structural changes. Nonetheless, in a low threshold service the application of barriers might create a potential conflict between ease of access, confidentiality and safety [16]. Due to the symbolic function of space and barriers, glass partitions might adversely affect patient-staff relationships, exacerbate violence and increase staff fearfulness $[17,18]$. This needs further exploration.

Monitoring systems are highly recommended to prevent occupational violence and consequences thereof $[1,16,18]$, and seemed to be prevalent at the EPCCs. However, the preparation for negative incidents through training was less common. Violence-prevention training is deemed important and useful to prevent workplace violence in the health sector [18-20], and can probably be made available to all relevant staff independent of the size of the institution.

Having an alarm system to alert colleagues or others in the event of a problem is strongly recommended $[18,19]$, and should possibly be a minimum recommendation. Four 
per cent of the EPCCs had no alert system, which seriously restricts the workers' ability to summon help when needed. The reliance on the alarm on the national medical radio network, which is not primarily a safety tool, was more frequently reported among EPCCs with one GP working alone compared to other EPCCs. A previous study has shown that rural GPs use the medical radio network more frequently than their urban counterparts, and that they attend emergency situations more frequently than their urban colleagues [21]. In the smallest EPCCs the GP is based at home and attends the EPCC only when a consultation is needed. Some of the safety measures suggested in the 22-item list, such as security guard and personnel continuously accessible for patients/visitors, have low relevance for this type of organisation, and their absence might not be a safety risk for the GP. Nevertheless, focus on personnel safety is important independent of the organisation's size, especially as these sole GPs are the most vulnerable should a violent incident occur.

\section{Conclusion}

This study shows a considerable variation between Norwegian EPCCs regarding applied preventive measures, and a higher prevalence of such measures in EPCCs staffed with several health personnel around-the-clock. One should pay attention to the findings that in $70 \%$ of the EPPCs the GPs work alone for at least some of the time during opening hours, and that less than half of the EPCCs have systematic training regarding violence against personnel. More information is needed to judge the effectiveness of different measures and to make more appropriate recommendations. Given the variation in organisation and size of the EPCCs, we cannot assume that all suggested measures should be implemented everywhere. Even though some EPCCs have applied many preventive measures regarding workplace safety, we do not know if this makes any difference to the actual number of violent incidents or only to the subjective experience or consequences of the incidents. Further research should therefore focus on the experienced benefits of applied preventive measures.

\section{Competing interests}

The authors declare that they have no competing interests.

\section{Authors' contributions}

Both authors participated in the design of the study. TM collected and analysed the data. Both authors drafted and edited drafts of the manuscript, and approved the final version.

\section{Acknowledgements}

The study was funded by the National Centre for Emergency Primary Health Care, Uni Health, Uni Research, Bergen, Norway. The authors would like to thank all EPCCs that participated in the study.

Received: 28 February 2013 Accepted: 30 September 2013 Published: 3 October 2013

\section{References}

1. Norwegian Labour Inspection Authority: Vold og trusler på arbeidsplassen: Forebygging, håndtering og oppfolging (Violence and threats at the workplace. Prevention, Management and Follow-up). Norwegian; 2009. http://www. arbeidstilsynet.no/brosjyre.html?tid=103729 (last accessed 14 October 2013).

2. Joa TS, Morken T: Violence towards personnel in out-of-hours primary care: a cross-sectional study. Scand J Prim Health Care 2012, 30:55-60.

3. Lov om kommunale helse-og omsorgstjenester m.m (Act relating to the municipal health care services) 24.06.2011 No 30. Norwegian; 2013. http:// www.lovdata.no/all/hl-20110624-030.html (last accessed 26 February 2013).

4. Morken T, Hansen EH, Hunskaar S: Legevaktorganisering i Norge: rapport fra nasjonalt legevaktregister 2009 (Organisation of the out-of-hours services in Norway 2009). Norwegian: Bergen: National Centre for Emergency Primary Care, Uni Health; 2009. Report No. 8-2009.

5. Zakariassen E, Hunskaar S: Involvement in emergency situations by primary care doctors on-call in Norway-a prospective population-based observational study. BMC Emerg Med 2010, 10:5

6. Hansen EH, Zakariassen E, Hunskaar S: Sentinel monitoring of activity of out-of-hours services in Norway in 2007: an observational study. BMC Health Serv Res 2009, 9:123.

7. Arimatsu M, Wada K, Yoshikawa T, Oda S, Taniguchi H, Aizawa Y, Higashi T: An epidemiological study of work-related violence experienced by physicians who graduated from a medical school in Japan. $J$ Occup Health 2008, 50:357-361.

8. Myerson S: Violence to general practitioners and fear of violence. Fam Pract 1991, 8:145-157.

9. Tolhurst H, Talbot J, Baker L, Bell P, Murray G, Sutton A, Dean C, Treloar C, Harris G: Rural general practitioner apprehension about work related violence in Australia. Aust J Rural health 2003, 11:237-241.

10. Johansen $I H$, Carlsen $B$, Hunskaar S: Psychiatry out-of-hours: a focus group study of GPs' experiences in Norwegian casualty clinics. BMC Health Serv Res 2011, 11:132.

11. Vold og trusler på legekontoret: Fagutvalgets hefte om forebygging og håndtering av vold og trusler mot helsepersonell (Violence and Threats in the Doctor's Office: Booklet about Prevention and Managing Violence and Threats towards Health Personnel). Norwegian; 2003. http://legeforeningen.no/yf/ Allmennlegeforeningen/Publikasjoner/vold-og-trusler-pa-legekontoret/ (last accessed 26 February 2013).

12. Lov om medisinsk og helsefaglig forskning (the Health Research Act). 20.06.2008 No. 44. Norwegian. http://www.lovdata.no/all/hl-20080620-044. html (last accessed 25 April 2013).

13. Lau JB, Magarey J, Wiechula R: Violence in the emergency department: an ethnographic study (part I). Int Emerg Nurs 2012, 20:69-75.

14. McPhaul KM, Lipscomb JA: Workplace violence in health care: recognised but not regulated. Online J Issues Nurs 2004, 9:7.

15. National Centre for Emergency Primary Care: Er hjelpa nærmast! Forslag til Nasjonal handlingsplan for legevakt (... is help closest! Suggestions for a national action plan for out of hours primary care centres). Norwegian: Bergen: National Centre for Emergency Primary Care, Uni Health; 2009. Report No 1-2009.

16. Wright NM, Dixon CA, Tompkins CN: Managing violence in primary care: an evidence-based approach. Br J Gen Pract 2003, 53:557-562.

17. Magin P, Joyce T, Adams J, Goode S, Cotter G: General practice as a fortress-occupational violence and general practice receptionists. Aust Fam Physician 2010, 39:854-856.

18. Russi M, Buchta WG, Swift M, Budnick LD, Hodgson MJ, Berube D, Kelafant $\mathrm{GA}$ : Guidance for occupational health services in medical centers. J Occup Environ Med 2009, 51:1e-18e.

19. ILO/ICN/WHO/PSI: Framework guidelines for addressing workplace violence in the health sector. Geneva: International Labour Office; 2002.

20. Wassell JT: Workplace violence intervention effectiveness: a systematic literature review. Saf Sci 2009, 47:1049-1055.

21. Zakariassen E, Sandvik H, Hunskaar S: Norwegian regular general practitioners' experiences with out-of- hours emergency situations and procedures. Emerg Med J 2008, 25:528-533.

doi:10.1186/1472-6963-13-384

Cite this article as: Morken and Johansen: Safety measures to prevent workplace violence in emergency primary care centres-a cross-sectional study. BMC Health Services Research 2013 13:384. 